\title{
Penalizing Cartels: The Case for Basing Penalties on Price Overcharge $^{1}$
}

\author{
Yannis Katsoulacos ${ }^{2}$ \\ Evgenia Motchenkova ${ }^{3}$ \\ David Ulph ${ }^{4}$
}

\begin{abstract}
In this paper we set out the welfare economics based case for imposing cartel penalties on the cartel overcharge rather than on the more conventional bases of revenue or profits (illegal gains). To do this we undertake a systematic comparison of a penalty based on the cartel overcharge with three other penalty regimes: fixed penalties; penalties based on revenue, and penalties based on profits. Our analysis is the first to compare these regimes in terms of their impact on both (i) the prices charged by those cartels that do form; and (ii) the number of stable cartels that form (deterrence). We show that the class of penalties based on profits is identical to the class of fixed penalties in all welfare-relevant respects. For the other three types of penalty we show that, for those cartels that do form, penalties based on the overcharge produce lower prices than those based on profit)while penalties based on revenue produce the highest prices. Further, in conjunction with the above result, our analysis of cartel stability (and thus deterrence), shows that penalties based on the overcharge out-perform those based on profits, which in turn out-perform those based on revenue in terms of their impact on each of the following welfare criteria: (a) average overcharge; (b) average consumer surplus; (c) average total welfare.
\end{abstract}

JEL Classification: L4 Antitrust Policy, K21 Antitrust Law, D43 Oligopoly and Other Forms of Market Imperfection, $\mathrm{C} 73$ Stochastic and Dynamic Games; Repeated Games

Keywords: Antitrust Enforcement, Antitrust Law, Cartel, Oligopoly, Repeated Games.

\footnotetext{
${ }^{1}$ We are grateful to Joe Harrington and Giancarlo Spagnolo and particularly Yossi Spiegel for very helpful comments and suggestions. We would also like to thank the participants of a seminar at the Sauder School of Business, University of British Columbia (September 2014) - particularly Jim Brander, Tom Davidoff, Tom Ross and Ralph Winter - and at the session on the "Enforcement of Competition Policy" in the $9^{\text {th }}$ CRESSE Annual Conference (Corfu, 4 - 6 July 2014) for helpful suggestions and comments. All inaccuracies and omissions remain our sole responsibility. Yannis Katsoulacos acknowledges that this research has been co-financed by the European Union (European Social Fund - ESF) and Greek national funds through the Operational Program "Education and Lifelong Learning" of the National Strategic Reference Framework (NSRF) - Research Funding Program: ARISTEIA - CoLEG. Also we acknowledge support from the Tinbergen Institute, VU University Amsterdam, Short-term Visitor Program.

${ }^{2}$ Department of Economic Science, Athens University of Economics and Business, Patission 76, Athens 104 34, Greece, Email: katsoul@aueb.gr or ysk@hol.gr

${ }^{3}$ Department of Economics, VU University Amsterdam, TILEC and Tinbergen Institute, De Boelelaan 1105, 1081 HV Amsterdam, The Netherlands, Email: emotchenkova@feweb.vu.nl

${ }^{4}$ University of St Andrews, School of Economics and Finance, St Andrews, Fife, KY16 9AR, Scotland, UK; Director Scottish Institute for Research in Economics (SIRE), Email: du1@st-andrews.ac.uk
} 


\section{Introduction}

Cartels are still very active throughout the world and pervasive in a wide variety of markets - despite increased enforcement in the form of much higher fines and other sanctions and the implementation of leniency policies. Empirical evidence reviewed in Levenstein and Suslow $(2011,2012,2014)$ also suggests that, while antitrust is the most important force leading to cartel break-up, there are limitations to the effectiveness of these policies as currently designed. ${ }^{5}$ In this paper, we argue that the widely employed current designs of one of the most important enforcement tools in the fight against cartels- namely monetary penalties are flawed and that this does indeed limit the effectiveness of this tool. We propose an alternative design that could significantly improve the effectiveness of monetary penalties. Specifically, our objective is to set out the welfare economics framework that supports the case for Competition Authorities to switch the base on which penalties for cartels are set away from the conventional bases of revenue or illegal gains and instead to base the penalty on the cartel overcharge. Our reason for choosing to examine this alternative penalty base is that, consistent with the prescriptions of second-best welfare economics, this policy is targeted at the underlying distortion generated by cartels - the increase in price. ${ }^{6}$

To make this case we examine various penalty regimes that have been widely considered in the literature and analyse their impact on: (i) the price charged by any stable cartel that forms; (ii) cartel stability/deterrence - i.e. the number of stable cartels that form; and finally (iii) the overall level of welfare induced by the penalty regime. ${ }^{7} \mathrm{We}$ characterise a penalty regime by (a) its toughness - the probability of detection and the penalty rate; (b) the penalty base to which this penalty rate applies.

We use a repeated Bertrand oligopoly model that allows us to compare both the price and the deterrence effects of the four major types of fining structures investigated in the literature. These four types are: fines based on revenue (see e.g. Bageri et al. (2013) and Katsoulacos and Ulph (2013)); fines based on illegal gains (see e.g. Harrington (2004, 2005), Houba et al. (2010, 2012) or Hunold (2013)); fines based on cartel overcharge (see

\footnotetext{
${ }^{5}$ See in particular the recent series of papers by Levenstein and Suslow $(2011,2012,2014)$ that contain reviews and extensive references to the relevant literature.

${ }^{6}$ By contrast the alternative penalty bases - revenue or illegal gains/profits - while also depending on the cartel overcharge also depend on the cartel output, which in turn depends negatively on the cartel price thus diluting the incentive to lower prices.

${ }^{7}$ The impact of the toughness of the penalty regime on the cartel pricing behavior has been addressed in Katsoulacos and Ulph (2013). However, they have relied on a static game, have not analyzed the impact of the penalty structure on cartel stability and have not examined the deterrence implication of the various penalty structure employed in practice, as we do here. In his seminal article, Harrington (2005) has also shown that price dependent penalties (that are based on damages) imply that the steady state cartel price will be below the simple monopoly price and that the toughness of the penalty regime (the size of the damage multiplier) is one of the factors that reduce the equilibrium cartel price. However, he does not provide comparisons of all the alternative penalty regimes examined here. Also, and most importantly, the possible deterrence effects of various penalty structures in conjunction with their direct price effects have not been systematically analyzed in literature on antitrust so far.
} 
e.g. Buccirossi and Spagnolo (2007) and Katsoulacos and Ulph (2013));and fixed fines (see e.g. Rey (2003) or Motta and Polo (2003)).

While other papers have considered the properties of each of the four penalty regimes and made some limited comparisons between them, a major contribution of this paper is to undertake a systematic comparison of all four regimes in terms of their impact on both the prices set by those stable cartels that do form and deterrence/cartel stability (i.e. the number of stable cartels that form).

We also make two important methodological contributions.

- First, we extend the repeated Bertrand model in Houba et al. $(2010,2012)$ to capture the effect of the cartel stability condition on cartel pricing behavior. In particular, since we have cases where the cartel price may be above the monopoly price, we have developed a more general model of the price-setting behaviour of a defector. This allows us to bridge the standard critical discount factor approach to the analysis of collusion (see e.g. Tirole (1988) or Motta and Polo (2003)) to profit maximizing decisions by the stable cartels (with continuum of prices, which can be chosen by the cartel). This latter approach has been proposed in e.g. Block et al. (1981) or Harrington $(2004,2005)$.

- Second, we provide a framework within which we integrate the impact of penalty regimes on the price setting behaviour of cartels that do form with their deterrent effects and this provides an evaluation of the overall impact of different penalty regimes.

Our first result is that the class of profits-based penalties is identical to the class of fixed penalties in terms of all the welfare-relevant outcomes they produce - price, deterrence. Anything that can be achieved by one type of penalty can be achieved by the other using an equivalent level of penalty. Consequently we confine attention to three penalty regimes - those based on profits, those based on revenue, and those based on the cartel overcharge.

In terms of the price set by those stable cartels that do form, we show that proportional fines based on overcharges are more successful in terms of their effect on price when compared to fines based on revenues or illegal gains. ${ }^{8}$ Specifically, we show that:

- penalties based on illegal gains lead cartels to set the monopoly price - however tough the regime;

- if the penalty is imposed on revenue then: (a) the cartel price will be above the monopoly price;(b) the cartel price will be higher the tougher the regime;

- if the penalty is imposed on overcharge then: (a) the cartel price will be below the monopoly price; (b) the need to maintain cartel stability requires the cartel to set its price at or below a maximum price which decreases towards the competitive price as

\footnotetext{
${ }^{8}$ Apart from the trivial case where either the probability of detection or the penalty rate is zero, in which case there is effectively no penalty regime and it does not matter on which base the non-existent penalty might have been based.
} 
it becomes increasingly difficult to maintain stability; (c) the cartel price will be lower the tougher the regime.

Turning to the deterrence impact of different penalty structures, we show that, as expected, in each regime the tougher the penalty the greater is the degree of deterrence.

A major contribution of this paper is to combine deterrence effects with an analysis of the prices set by those cartels that do form to provide an overall assessment of the impact of different regimes on prices, consumer surplus and total welfare (consumer plus producer surplus). But since both deterrence and the cartel price can depend on the toughness of the regime, it follows that in order to meaningfully compare the effects of using different penalty bases we need to ensure that each penalty regime is in some sense equally tough. ${ }^{9}$ We consider two concepts of equal toughness.

The first is deterrence equivalence: the same fraction of all stable cartels that could potentially form do in fact form. Given the above results on the prices set by cartels that do form, it is clear that under deterrence equivalence penalties on the overcharge outperform those on profits which in turn out-perform penalties based on revenue.

However competition authorities - and courts - are not concerned solely with deterrence, they also want penalties that are reasonable and proportionate. So the second criterion of equal toughness that we consider is that of penalty revenue equivalence: on average $^{10}$ the size of the penalty actually paid by any cartel that forms and is subsequently detected and penalized should be the same. We again demonstrate that in terms of average overcharge, average consumer surplus, and average total penalties on the overcharge out-perform those on profits which in turn out-perform penalties based on revenue.

Currently the revenue-based penalties is the norm in all major jurisdictions with caps that are based on either revenue (EU) or on illegal gains (US).Most other OECD countries follow the lead of the $\mathrm{US}^{11}$ and the $\mathrm{EU}^{12}$.

\footnotetext{
${ }^{9}$ As we will show, achieving a given level of toughness under a revenue based penalty regime requires the penalty rate to vary according to the elasticity of demand in the industry. An estimate of this can be obtained by the use of what Farrell and Shapiro (2008) have proposed in the case of mergers through the application of Critical Loss Analysis: "revealed preference information (to) make inferences about preferences based directly on observed choices". Here, and to paraphrase their argument in relation to mergers, "one can make inferences about demand sensitivity as gauged by ... real firm(s) based on (their collusive) choice of price.... The idea is captured by the Lerner equation".

${ }^{10}$ Since, as indicated, the price set by any cartel that does form under both a revenue-based penalty regime and an overcharge-based penalty regime will potentially vary depending on the intrinsic difficulty of holding the cartel together, so too will the actual penalty paid. So all we can require is that on average the penalty paid should be the same.

${ }^{11}$ In the US the process of their assessment begins with the calculation of a base fine. To determine the base fine, a percentage of the volume of affected commerce, that is, of total sales from the relevant market, is taken into account. The USSG suggests that $20 \%$ of the volume of affected commerce can be used as a good proxy. This volume of affected commerce covers the entire duration of the infringement. Once the amount of the base fine has been calculated, aggravating and mitigating elements are taken into consideration. However, the final fine for undertakings must not exceed a maximum statutory limit which is the greatest of 100 million USD or twice the gross pecuniary gains the violators derived from the cartel or twice the gross pecuniary loss caused to the victims.
} 
Our clear policy recommendation is therefore that Competition Authorities should switch to a penalty structure that uses the price overcharge as the base on which the penalty is imposed. ${ }^{13}$ In essence the reason is that overcharge based fines are preferable, since they target the price, which is causing the damage to consumers. Profit based fines are a weaker instrument since they do not target the price directly, but target firms' earnings, while revenue based fines have strongly counterproductive effects as originally also shown in Bageri et al. (2013) and Katsoulacos and Ulph(2013).

Overcharge-based fines are superior to currently employed penalty regimes at not just a theoretical welfare-economics level. It is likely that implementation of overcharge-based fines in practice is no more difficult than the next best alternative (in terms of welfare induced) - a profits-based penalty. ${ }^{14}$ Although establishing the counterfactual can be tricky, competition authorities have to obtain estimates anyway during the investigation in order to establish whether a group of firms really has driven up the price. And certainly such information is needed in order to obtain estimates of the overcharge, during damage claim procedures - developments in economics and econometrics make it possible to estimate cartel overcharges with reasonable precision or confidence. ${ }^{15} \mathrm{We}$ further discuss implementation issues below.

The rest of this paper is organized as follows. Section 2 outlines the model. In Section 3 we derive the main formulae for pricing, deterrence and various welfare indicators under each of the penalty regimes. In sections 4 we undertake a systematic comparison of the various regimes in terms of prices, deterrence and overall welfare. Section 5 concludes.

\footnotetext{
${ }^{12}$ In the EU under 2006 guidelines, fines are calculated in the following way: First, the Commission determines a basic amount which may be adjusted afterwards due to aggravating and mitigating elements. The basic amount is calculated by taking into account the undertaking's relevant turnover (of the last year of the cartel), the gravity and the duration of the infringement, as well as an additional amount of about $15 \%$ $25 \%$ of the value of sales in order to achieve deterrence. For cartels, the proportion of the relevant turnover is set at the higher end of the scale which is $30 \%$. However, the maximum amount of the fine imposed shall not exceed the cap of $10 \%$ of annual worldwide turnover of the undertaking in the preceding business year.See also 2006 EU Guidelines and Bageri et.al. (2013).

${ }^{13}$ It is important to note that in this paper we are concerned solely with the question of which of the various alternative penalty bases is superior in terms of its welfare implications and not with the different issue of whether current cartel penalty rates are or are not too high. There is an extensive theoretical and empirical literature on this latter question which is reviewed, for example, in Katsoulacos and Ulph (2013). Their results support the recent evidence by Allain et.al (2011) and Boyer et.al (2011) that current rates are not too low and indicate that higher rates (on a revenue base) will not necessarily lead to lower cartel prices.

${ }^{14}$ Bageri et. al. (2013) provide additional arguments to those presented below for preferring a profit-based penalty regime to a revenue-based regime (they do not consider an overcharge-based regime).

${ }^{15}$ For details see Brander and Ross (2006).
} 


\section{The Model}

In each of infinitely many periods, $n \geq 2$ firms compete in prices in a homogeneous oligopoly model with demand function $Q(p)$ where $p$ denotes price and $Q$ is the quantity supplied to the market. The associated inverse demand function is denoted $p=P(Q)$ and is assumed to have the standard property that both average and marginal revenue are strictly decreasing. Firms have identical constant unit costs of production $c, 0<c<P(0)$. We make the standard assumption that there are no efficiency effects from cartels and so firms' unit costs, $c$, are the same whether or not they are in the cartel.

We denote industry profits when the price is $p$ by $\pi(p, c)=(p-c) Q(p)$. The monopoly price associated with particular demand function and cost level $c$ is denoted as $p^{M}(c)=\arg \max _{p} \pi(p, c)$, where, given our assumptions, $c<p^{M}(c)<P(0)$ and $p^{M}(c)$ is

strictly increasing in $c$. The associated monopoly profits are denoted by $\pi^{M}(c)=\pi\left(p^{M}(c)\right)$, where $\pi^{M}(c)$ is strictly decreasing in $c$.

The important implications of this set-up are as follows. Firstly, in the absence of collusion, the competitive equilibrium would be the unique Bertrand-Nash equilibrium in which all firms set price at marginal cost, so $p^{N}=c$ and $\pi\left(p^{N}\right)=0 \cdot p^{N}$ is sometimes referred to as the "but-for" price - the counterfactual price that would have arisen in the absence of collusion. We also let $Q^{N}=Q\left(p^{N}\right)$ be the associated "but-for" level of output. Secondly, if a cartel forms then, in order for the cartel to be able to set a price above $p^{N}$, all $n$ firms have to be in the cartel.

We model the cartel as an infinitely-repeated collusive game supported by a simple grim trigger strategy profile, but in the presence of antitrust enforcement. ${ }^{16}$ In every period, the $n$ symmetric firms decide whether to collude and, if so, at what price. If the firms collude at price $p \geq c$, gross collusive (cartel) profits will be $\pi(p)=(p-c) Q(p) .^{17}$ So long as firms are colluding, then, with constant $^{18}$ probability $\beta, 0<\beta \leq 1$, in each period the CA may detect and successfully prosecute the cartel, in which case it imposes a penalty at the constant rate $\rho>0$ on a penalty base $B(p)$, which, as indicated, may vary with the price. Since our focus is on the effects of different penalty bases, we assume that both $\beta$ and $\rho$ are independent of the price, $p$, set by the cartel. We let $\tau=\beta \rho$ denote the toughness of the penalty regime.

\footnotetext{
${ }^{16}$ Several elements of this model are borrowed from the analysis in Houba, Motchenkova and Wen (2010, 2011, 2012).

${ }^{17}$ Given our assumptions, these will also represent the illegal gains from collusion - cartel profits minus the profits in the "but-for" situation.

${ }^{18}$ The assumption of a constant probability means that the probability is independent of the past history of detection.
} 
We consider a number of alternative bases that have been previously analysed: ${ }^{19}$

- fines on profits/ illegal gains: $B_{\pi}(p)=(p-c) Q(p)$;

- fines on revenue: $B_{R}(p)=p Q(p)$;

- fixed fines: $B_{F}(p) \equiv B_{0}{ }^{20}$

Notice that each of these penalty bases is denominated in units of currency. We will contrast all of these penalty bases with fines based on the overcharge. The priceovercharge is the extent to which price is raised above the "but-for" level. The overcharge can be expressed as the absolute increase in price, $\theta=p-p^{N}>0$, in which case, in order to have a penalty base that is denominated in units of currency we have to multiply the overcharge, $\theta$, by some measure of output, and the natural one to use is the "but-for" output, $Q^{N}$. So the final penalty base we consider is

- fines based on the overcharge: $B_{O}(p)=\left(p-p^{N}\right) Q^{N}=(p-c) Q^{N} .^{21}$

Within the framework of this model one could in principle obtain the first-best by imposing a Beckerian penalty - i.e. a profit-based penalty implemented with toughness $\tau=1 \Rightarrow \rho=\frac{1}{\beta}>1$ - since that will deter all cartels. Indeed, as we will see, an overchargebased penalty imposed with the same degree of toughness will also achieve the first best since the optimal price of any cartel that does form will then be $p=c$, and, anticipating this, all cartels will again be deterred. However, the premise of this paper is that such first-best penalty rates of over $100 \%$ are unrealistic since there are other factors such as proportionality, bankruptcy considerations, insufficient legal ceilings, and competition authorities' limited resources that come in to play in setting penalties. With lower (second-best) penalty rates some cartels will form and will set positive overcharges, and the issue of what penalty base to use becomes very important bearing in mind its impact on both deterrence and price behaviour. The characterisation of the second-best optimum taking account of the proportionality and other legal constraints but focusing on just price effects of formed cartels has been examined in the literature. ${ }^{22}$ In contrast to this literature here we recognise and take into account for the first time the effects of penalties on both

\footnotetext{
${ }^{19}$ Note that in practice penalties also depend on the duration of the cartel. In our analysis we are focusing on the steady-state penalties. However, incorporating duration introduces a number of complications that make the analysis less tractable without fundamentally affecting the results. For example we lose stationarity - see Harrington (2014), a paper that focuses on the implications of taking into account cartel duration. Katsoulacos and Ulph (2013) also recognise that competition authorities may detect a cartel either while it is still in existence or after it has fallen apart and show how this affects the optimal penalty rate.

${ }^{20}$ While the fixed fine is independent of the actual price, $p$, charged by the cartel, it may vary across cases or across different markets. One may think of it as a penalty based on some measure of the size of the market, e.g. the revenue $p^{N} Q^{N}$ earned at the "but-for" price.

${ }^{21}$ The same analysis holds, if we define overcharge as the percentage increase in price.

22 See e.g. Houba, Motchenkova, Wen $(2011,2014)$. Harrington $(2004,2005)$ also looks at price effects of various penalty structures.
} 
pricing behaviour and deterrence and then conduct an analysis that shows that provided penalties are in some sense equally tough, then whatever degree of toughness one chooses there is a clear welfare ranking of penalty bases: overcharge dominates profits, which in turn dominates revenue.

We also assume that, so long as no firm has deviated, firms continue to collude even if they were detected and paid a fine - which is consistent with profit maximizing behaviour. $^{23}$

Given these assumptions the expected present value of profits (net of penalties) to a single firm from participating in the collusive agreement, when the penalty is imposed on base $B(\cdot)$ with toughness $\tau$, can be expressed as

$$
V[p, \tau B(\cdot)]=\frac{\pi(p, c)-\tau B(p)}{n(1-\delta)}=\frac{\pi(p, c)-\tau B(p)}{\Delta},
$$

where $\delta, 0<\delta<1$ is the discount factor, and $\Delta=n(1-\delta)$ is what we call the intrinsic difficulty of holding the cartel together.

If a firm defects from the collusive agreement in a particular period it sets a price $p^{D}(p)<p$ that undercuts the cartel price and, for a single period, gets the entire industry profits at that lower price. Additionally, the defector incurs no penalty that would arise should the cartel be investigated and prosecuted in that period. ${ }^{24}$ However we assume that the other members of the cartel punish the defector by reverting to Nash behaviour for ever more. The defector will wish to obtain the greatest profits it can, so, if the cartel sets a price above the monopoly price $p^{M}(c)$ the defector will set the monopoly price, while, if the cartel sets a price at or below the monopoly price, the defector sets a price $p^{D}=p-\varepsilon ; \varepsilon>0, \varepsilon \approx 0$ that is as close as possible to the cartel price and so effectively takes the cartel profits. So formally we have:

$$
p^{D}(p, c)=\left\{\begin{array}{l}
p^{M}(c), \quad p>p^{M}(c) \\
p-\varepsilon, \quad p \leq p^{M}(c)
\end{array} ; \quad \pi^{D}(p, c)=\left\{\begin{array}{ll}
\pi^{M}(c), & p>p^{M}(c) \\
\pi(p, c), & p \leq p^{M}(c)
\end{array} .\right.\right.
$$

${ }^{23}$ If a stable cartel could profitably form before the detection then, since nothing has changed after detection, it will continue to be profitable to collude. A similar assumption that the cartel reestablishes after each conviction has been adopted in Motta and Polo (2003). However, other assumptions could be made. For example Harrington $(2004,2005)$ assumes that a cartel ceases to exist after detection. More generally Houba, Motchenkova and Wen $(2012,2015)$ assume that, after detection, there is a constant probability $\gamma, \quad 0 \leq \gamma \leq 1$ that the cartel will continue in existence after detection. In this case one simply replaces the term $\Delta=n(1-\delta)$ that appears in our analysis with the more general expression $\Delta_{\gamma}=n(1-\delta)\left[1+\frac{\beta \delta(1-\gamma)}{1-\delta}\right]$. However, for the issues with which we are dealing, nothing of substance is affected by this, so in what follows we will continue to assume that all cartels re-form after detection (i.e. $\gamma=1$ ).

${ }^{24}$ As in Motta and Polo (2003), we assume that price-deviating firms will not be prosecuted. Alternative assumptions are examined in Spagnolo (2004), Buccirossi and Spagnolo (2007), Chen and Rey (2012), Jansen and Sorgard (2014). However, adopting these different assumptions would not change the main conclusion of our paper about superiority of overcharge-based penalties, i.e. price effects remain similar. 
For a cartel to be stable it is necessary that

$$
\frac{\pi(p, c)-\tau B(p)}{\Delta} \geq \pi^{D}(p, c) \geq \pi(p, c) .
$$

We define the maximum critical difficulty, $\bar{\Delta}$, as the value of $\Delta$ at which the cartel stability condition just holds. Notice that if there is no antitrust enforcement, i.e. $\tau=0$, then the cartel stability condition just reduces to $\Delta \leq 1$, and we have the standard result that $\bar{\Delta}=1$. When there is enforcement, i.e. $\tau>0$, it will be more difficult to keep a given cartel together and the maximum critical level of difficulty falls, so we will have $\bar{\Delta}<1$. In the rest of the paper we confine attention to the values of $\Delta$ in the range $[0,1]$, which is the range over which cartels would exist in the absence of a competition authority. So we will use this range as a baseline relative to which we compare the effects of different penalty regimes. In the next section we will explore precisely how $\bar{\Delta}$ varies both within and across penalty regimes, and in particular how it varies with the toughness of the penalty regime, $\tau$.

When $\Delta \in[0, \bar{\Delta}]$ a stable cartel exists and we assume that the cartel sets a price that maximises the expected present value of profits, $V[p, \tau B(\cdot)]$ subject to the stability condition (3). As we will show, for some penalty regimes there may be values of $\Delta \in[0, \bar{\Delta}]$ for which the cartel stability condition bites, so the cartel price can potentially vary with $\Delta$ over this interval. So for all $\Delta \in[0, \bar{\Delta}]$ we formally define the cartel price as

$$
p^{C}[\Delta, \tau B(\cdot)]=\underset{p}{\arg \max } \frac{\pi(p, c)-\tau B(p)}{\Delta} \text { subject to } \frac{\pi(p, c)-\tau B(p)}{\Delta} \geq \pi^{D}(p, c)
$$

An immediate conclusion which provides insight into why the cartel price is above or below the monopoly price in the different regimes is:

Lemma 1 When the stability condition does not bite

$$
p^{C}[\Delta, \tau B(.)]<p^{M}(c) \Leftrightarrow B^{\prime}\left[p^{M}(c)\right]>0 .
$$

Proof: This follows immediately from the analysis of the value function derivative in (1): $p^{C}[\Delta, \tau B()]<.p^{M}(c)$ iff $V^{\prime}\left(p^{M}(c)\right)<0 \quad \Leftrightarrow \quad \pi^{\prime}\left(p^{M}(c)\right)<\tau B^{\prime}\left(p^{M}(c)\right) \quad$ or $\quad B^{\prime}\left(p^{M}(c)\right)>0$.

This provides an insight into the properties that any penalty base has to satisfy in order to have the property that the price set by those cartels that do form is below the monopoly price they would have set in the absence of any antitrust enforcement.

To get an overall picture of the impact of a penalty regime on both deterrence and the price set by those cartels that do form, we consider all values of $\Delta \in[0,1]$ and define what we call the overall price $p[\Delta, \tau B(\cdot)]$ as 


$$
p[\Delta, \tau B(\cdot)]=\left\{\begin{array}{l}
p^{C}[\Delta, \tau B(\cdot)], \quad \Delta \in[0, \bar{\Delta}] \\
p^{N}=c, \quad \Delta \in[\bar{\Delta}, 1]
\end{array} .\right.
$$

Then, assuming that $\Delta$ is uniformly distributed on [0,1], we can use (5) to calculate the average overcharge; the average consumer surplus; the average total welfare ${ }^{25}$ associated with any penalty regime.

Our objective is to understand how various penalty regimes as characterised by the toughness of the penalty, $\tau$, and the penalty base $B(p)$ affect: (a) cartel stability/deterrence as captured by $\bar{\Delta}<1$; (b) the price, $p^{C}[\Delta, \tau B(\cdot)]$ set by those stable cartels that form when $\Delta \in[0, \bar{\Delta}]$. From this we can derive the impact of these regimes on the overall price $p[\Delta, \tau B(\cdot)]$ and, hence, on average overcharge, average, consumer surplus and average total welfare.

\section{Cartel Pricing, Cartel Stability and Welfare}

The existing literature has not examined the implications of antitrust penalties for cartel stability in a systematic manner. In this section we fill in this gap by deriving the impact of each of the four alternative types of fine structures identified above on cartel pricing and on cartel stability (by which we mean the maximum critical difficulty of holding a cartel together). We combine these into a number of measures of overall/average welfare. We index the four penalty bases by $b \in\{\pi, F, R, O\}$ and allow the possibility that the penalty rate, $\rho$, and hence toughness, $\tau$ differs depending on which base is used.

\subsection{Penalty on Profits and Fixed Penalty}

Here the penalty base is $B_{\pi}(p)=(p-c) Q(p)$, so if the toughness of this regime is $\tau_{\pi}$ the stability condition (3) becomes

$$
V\left[p, \tau_{\pi} B_{\pi}(\cdot)\right]=\frac{\left(1-\tau_{\pi}\right)(p-c) Q(p)}{\Delta} \geq \pi^{D}(p, c)
$$

Notice that in order for there to be any $p, c \leq p \leq P(0)$, for which the cartel stability condition (6) holds it is necessary that $0 \leq \tau_{\pi} \leq 1$.

${ }^{25}$ Recall that CS and welfare are defined by $C S(p)=\int_{p}^{\infty} Q(z) d z$ and $T W(p)=C S(p)+(p-c) Q(p)$ and, for any $p, c \leq p<P(0)$ are strictly decreasing functions of $p$. 
It clearly follows from (6) that maximizing the net present value of profits is equivalent to maximizing gross profits, and so to setting the monopoly price. Consequently the maximum critical difficulty under a profits-based penalty regime that is implemented with toughness $\tau_{\pi}, \quad 0 \leq \tau_{\pi} \leq 1$ is

$$
\bar{\Delta}_{\pi}\left(\tau_{\pi}\right)=1-\tau_{\pi} \leq 1 .
$$

and so for those stable cartels that do form - i.e. for $0 \leq \Delta \leq 1-\tau_{\pi}$ the cartel price is:

$$
p_{\pi}^{C}\left(\Delta, \tau_{\pi}\right)=\underset{p}{\arg \max } V\left[p, \tau_{\pi} B_{\pi}(\cdot)\right]=p^{M}(c) .^{26}
$$

Thus fines based on profits/illegal gains induce the cartel to set the monopoly price $p^{M}(c)$, independently of the toughness of the penalty regime. ${ }^{27}$ This is because the penalty just produces an equi-proportionate reduction in net expected profits. So maximizing net profits is equivalent to maximizing gross profits and the price that is set is the same as that which would have arisen had no penalty regime been in place - the monopoly price.

Combining the deterrence effect with the cartel pricing we obtain the following proposition.

Proposition 1: When the penalty base is profit and the penalty is implemented with toughness $\tau_{\pi}$ then:

(a) the maximum critical level of difficulty is:

$$
\bar{\Delta}_{\pi}\left(\tau_{\pi}\right)=1-\tau_{\pi}
$$

(b) for $\Delta \in[0,1]$ the overall price is:

$$
p_{\pi}\left(\Delta, \tau_{\pi}\right)=\left\{\begin{array}{l}
p^{M}(c), \quad 0 \leq \Delta \leq 1-\tau_{\pi} \\
c, \quad 1-\tau_{\pi} \leq \Delta \leq 1
\end{array} .\right.
$$

The overall price is illustrated in Figure 1 below.

\footnotetext{
${ }^{26}$ This conclusion is consistent with the result in Lemma 1 , since obviously, under a profit-based penalty regime $B_{\pi}{ }^{\prime}\left[p_{\pi}^{C}\left(\Delta, \tau_{\pi}\right)\right]=B_{\pi}^{\prime}\left[p^{M}(c)\right]=0$.

${ }^{27}$ Houba et al. (2010) and Bageri et.al (2013) obtain similar results and Hunold (2013) obtains a similar result in a setting with upstream and downstream collusion. However, his analysis is different since he uses a static model without taking into account cartel stability condition. We go beyond Hunold (2013) static analysis by taking into account cartel stability and the deterrence effect of antitrust penalties (and not only price effect as is done in most of the existing literature).
} 


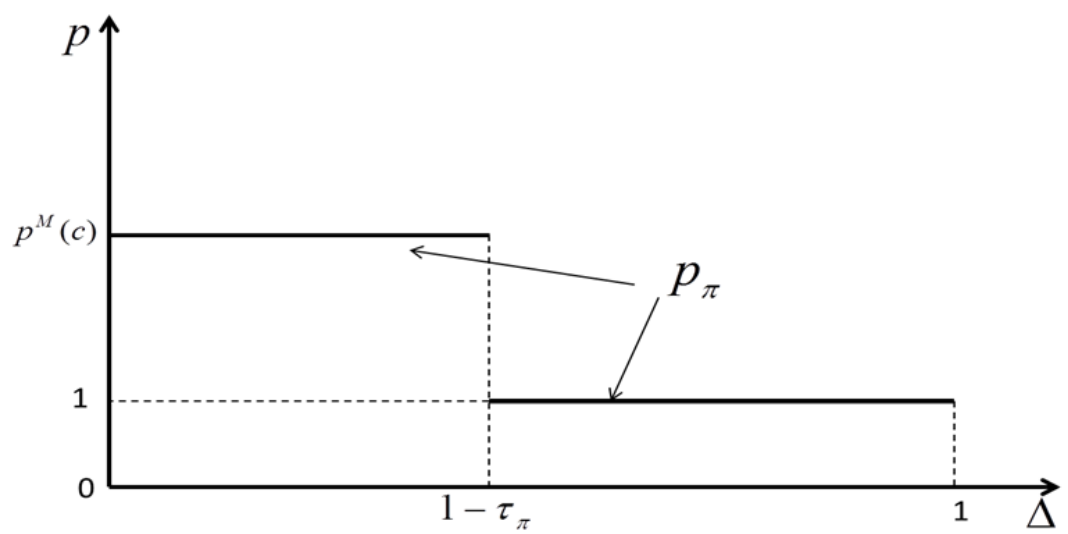

Figure 1: Overall Price under Profits-Based Penalty

Notice that if, for some reason - Cournot competition, product differentiation etc. - the but-for price were above marginal cost then illegal gains would be smaller than actual profits. This will imply that under a penalty based on illegal gains the collusive price will be below that produced by a penalty on profits because the reduction in penalty is proportional to cartel output, so giving the cartel an incentive to expand output and lower price. ${ }^{28}$ However, because the overcharge-based penalty focuses directly on the distortion caused by cartel price-setting behaviour the intuition given above suggests that it will still outperform a penalty based on illegal gains. A thorough analysis of this more general setting remains an interesting research question.

Finally, we show that a fixed penalty regime is effectively identical to a profitbased regime. If there is some fixed monetary penalty $B_{0}$, then the expected present value of net profits is $\frac{(p-c) Q(p)-\beta B_{0}}{\Delta}$. Maximising this would lead the cartel to set the monopoly price ${ }^{29} p^{M}(c)$ - essentially because the penalty operates like a fixed cost and so has no impact on pricing decisions, which are based on marginal costs. From (2) the profits from defecting would therefore be the cartel/monopoly profits, and so the cartel stability condition (3) becomes $\frac{\pi^{M}(c)-\beta B_{0}}{\Delta} \geq \pi^{M}(c)$, i.e. $\Delta \leq 1-\frac{\beta B_{0}}{\pi^{M}(c)}$. So any outcome that can be achieved by a profit-based regime with penalty rate $\rho_{\pi}$ can be achieved by a fixed penalty $B_{0}=\rho_{\pi} \pi^{M}(c)$, and conversely any outcome that can be achieved by a fixed penalty regime can be achieved by a profits-based penalty regime implemented with toughness $\tau_{\pi}=\beta B_{0} / \pi^{M}(c)$. In what follows we will therefore ignore fixed penalty regimes and confine our attention solely to a comparison of profits-based penalty regimes, revenue-based regimes and overcharge-based regimes.

\footnotetext{
${ }^{28}$ We are grateful to Joe Harrington for helpful discussions on this issue.

${ }^{29}$ Harrington (2005) shows that if the probability of detection and the penalty rate are constant then the same result holds in more general setting.
} 


\subsection{Penalty on Revenue}

If the penalty base is $B_{R}(p)=p Q(p)$, and the penalty rate is $\rho_{R}$, i.e. $\tau_{R}=\beta \rho_{R}$, the expected present value of net profits becomes

$$
V\left[p, \tau_{R} B_{R}(\cdot)\right]=\frac{\left(1-\tau_{R}\right) p Q(p)-c Q(p)}{\Delta}=\frac{\left(1-\tau_{R}\right)\left[p Q(p)-\frac{c}{1-\tau_{R}} Q(p)\right]}{\Delta} .
$$

So the effect of the penalty can be thought of in two ways: (i) it brings about an equiproportionate reduction in the cartel's revenue - but leaves the cartel costs unaffected; or (ii) it raises the cartel's costs and then imposes an equi-proportionate reduction in the resulting profits. Either way it leads to a reduction in marginal revenue relative to costs and so a reduction in output below the monopoly output and a price above the monopoly price. ${ }^{30}$ In fact it follows immediately from optimization in (10) that, when the stability condition (3) is not binding, the unconstrained profit-maximizing cartel price is ${ }^{31}$

$$
p^{M}\left(\frac{c}{1-\tau_{R}}\right)=\underset{p}{\arg \max }\left[p Q(p)-\frac{c}{1-\tau_{R}}\right]>p^{M}(c) .
$$

But then from (2) the defection price is $p^{M}(c)$ and the defection profits are $\pi^{M}(c)$. So the stability condition (3) will not bite provided

$$
\frac{\left(1-\tau_{R}\right) \pi^{M}\left(\frac{c}{1-\tau_{R}}\right)}{\Delta}>\pi^{M}(c)
$$

So we have established:

Proposition 2: When the penalty base is revenue and the penalty is implemented with toughness $\tau_{R}$ then:

(a) the maximum critical level of difficulty is:

$$
\bar{\Delta}_{R}\left(\tau_{R}\right)=\frac{\left(1-\tau_{R}\right) \pi^{M}\left(\frac{c}{1-\tau_{R}}\right)}{\pi^{M}(c)}<1-\tau_{R}
$$

(b) for $\Delta \in[0,1]$ the overall price is:

\footnotetext{
${ }^{30}$ An alternative intuition as to why the cartel price is above the monopoly price is that since marginal revenue at the monopoly output is positive, reducing output below this level will reduce the size of the expected penalty when the penalty is based on revenue.

${ }^{31}$ Note that when the penalty base is revenue, $B_{R}{ }^{\prime}\left[p^{M}(c)\right]=c Q^{\prime}\left[p^{M}(c)\right]<0$, so this result is consistent with Lemma1.
} 


$$
p_{R}\left(\Delta, \tau_{R}\right)=\left\{\begin{array}{l}
p^{M}\left(\frac{c}{1-\tau_{R}}\right), \quad 0 \leq \Delta \leq \bar{\Delta}_{R}\left(\tau_{R}\right) \\
c, \quad \bar{\Delta}_{R}\left(\tau_{R}\right) \leq \Delta \leq 1
\end{array} .\right.
$$

The overall price is illustrated in Figure 2 below.



Figure 2: Overall Price under Revenue-Based Penalty

\subsection{Penalty on Overcharge}

If the penalty base is $B_{O}(p)=(p-c) Q^{N}$, and the penalty rate is $\rho_{O}$, i.e. $\tau_{O}=\beta \rho_{O}$, then, from (1), the expected present value of net profits of a cartel member is:

$$
V\left[p, \tau_{O} B_{O}(\cdot)\right]=\frac{(p-c) Q(p)-\tau_{o}(p-c) Q^{N}}{\Delta}=\frac{(p-c)\left[Q(p)-\tau_{o} Q^{N}\right]}{\Delta} .
$$

We want to know whether the cartel price is above or below the monopoly price and hence, from (2), what the defection price and profit will be. We begin by characterizing the profit-maximising price and output for the case where the stability condition does not bite. Formally, the unconstrained profit-maximizing price is given by

$$
\hat{p}_{O}\left(\tau_{O}\right)=\arg \max _{p}\left[\pi(p)-\tau_{O}(p-c) Q^{N}\right]<p^{M}(c) .
$$

Note that $\hat{p}_{O}\left(\tau_{O}\right)$ is defined implicitly by the condition $\pi^{\prime}(p)-\tau_{o} Q^{N}=0$, and so by standard comparative static arguments, will be a strictly decreasing function of $\tau_{O}$. However, for later purposes it helps to characterize the unconstrained price in a different way. Let

$$
\widehat{Q}_{O}\left(\tau_{O}\right)=\underset{Q}{\arg \max }[P(Q)-c]\left(Q-\tau_{o} Q^{N}\right) ; \quad \hat{p}_{O}\left(\tau_{O}\right)=P\left[\hat{Q}_{o}\left(\tau_{O}\right)\right] .
$$


Define $\widetilde{M R}(Q)=P(Q)+P^{\prime}(Q)\left(Q-\tau_{O} Q^{N}\right)$ and notice that:

(i) $Q=\tau_{O} Q^{N} \Rightarrow \widetilde{M R}(Q)=P(Q)$;

(ii) $Q<\tau_{O} Q^{N} \Rightarrow \widetilde{M R}(Q)>P(Q)$

(iii) $Q>\tau_{O} Q^{N} \Rightarrow \widetilde{M R}(Q)<P(Q)$.

Then the first-order condition for the maximisation in (17) is

$$
\widetilde{M R}\left[\widehat{Q}_{O}\left(\tau_{O}\right)\right]=c=M C \text {. }
$$

This is illustrated in Figure 3 below.

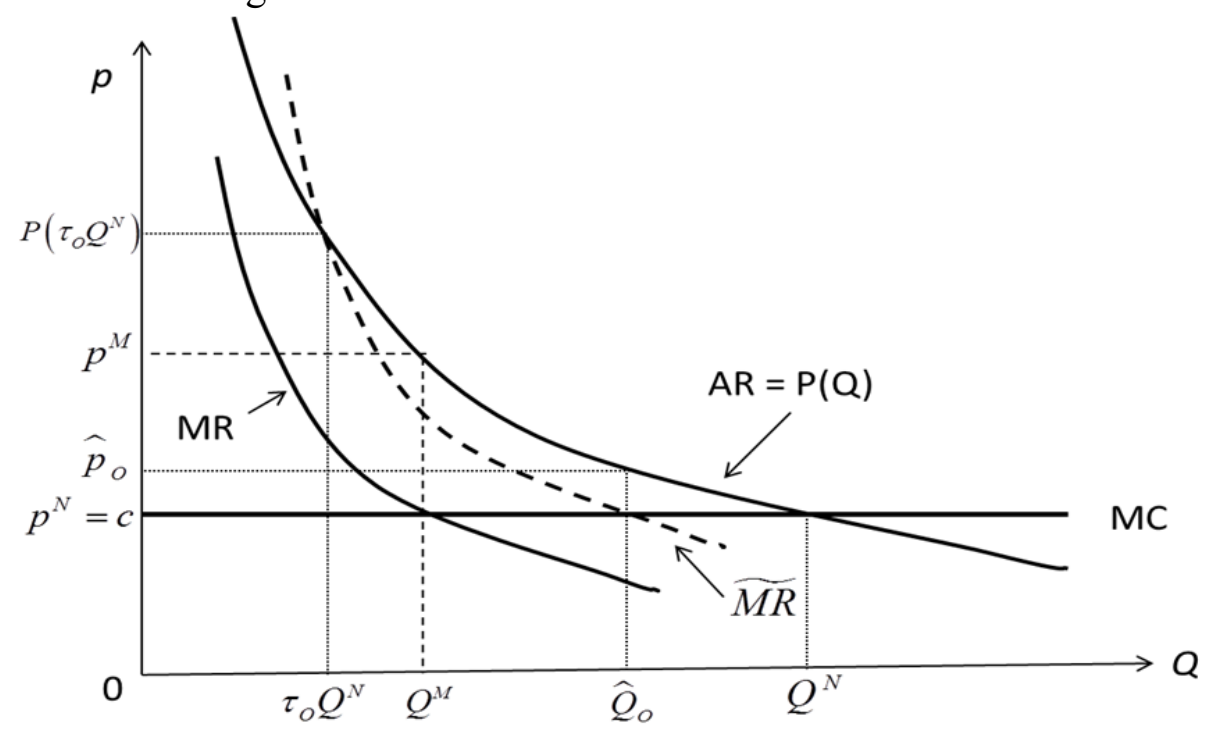

Figure 3: Optimum Price and Output under Overcharge-Based Regime

We then have

Proposition 3: When there is an overcharge-based penalty regime implemented with toughness $\tau_{O}, \quad 0<\tau_{O}<1$, then the unconstrained cartel price, $\hat{p}_{O}\left(\tau_{O}\right)$ satisfies :

(a) $c<\hat{p}_{O}\left(\tau_{O}\right)<p^{M}(c)$

(b) $\frac{d \hat{p}_{O}}{d \tau_{O}}<0$.

Proof: Both (a) and (b) follow immediately from Figure 3.

From (16), (2) and (3) it follows that the cartel stability condition is

$$
\frac{(p-c)\left[Q(p)-\tau_{o} Q^{N}\right]}{\Delta} \geq(p-c) Q(p)
$$

Provided $p>c$ and so the cartel sets a price above the but-for price, we can divide both sides of $(20)$ by $(p-c)$ to obtain: 


$$
Q(p) \geq \frac{\tau_{O} Q^{N}}{1-\Delta} \Leftrightarrow p \leq P\left(\frac{\tau_{O} Q^{N}}{1-\Delta}\right)
$$

So, in order to maintain stability, the cartel may be constrained to keep its price below some maximum level (equivalently keep its output above some minimum level). ${ }^{32}$ Therefore we have the following result:

Proposition 4: When penalties are imposed on the overcharge then cartel stability requires that the cartel should not set the price above the maximum price

$$
p_{O}^{M A X}(\Delta)=P\left(\frac{\tau_{O} Q^{N}}{1-\Delta}\right) .
$$

\section{Corollary:}

(i) The maximum price is a strictly decreasing function of: (a) the toughness of the penalty regime, $\tau_{O}$;(b) the difficulty of holding cartel together, $\Delta$.

(ii) Furthermore

$$
p_{O}^{M A X}(0)=P\left(\tau_{O} Q^{N}\right)>\hat{p}_{O}\left(\tau_{O}\right) ; \quad p_{O}^{M A X}(\Delta) \rightarrow c \text { as } \Delta \rightarrow 1-\tau_{O}
$$

Proof: (i) This follows immediately from the fact the inverse demand function $P(Q)$ is strictly decreasing, while the term $\frac{\tau_{O} Q^{N}}{1-\Delta}$ is increasing in both $\tau_{O}$ and $\Delta$.

(ii) The first part of this statement follows from Figure 3, and the second from the fact that $P\left(Q^{N}\right)=c$.

The intuition behind this result is simple. Suppose the cartel is just exactly on the cusp of stability, then an increase in $\Delta$ will, other things being equal, make the cartel unstable. The way to restore stability in the case of overcharge-based penalty is to reduce the penalty by cutting the price/overcharge.

From (18) and (23) it follows that there is a unique $\widetilde{\Delta}_{O}\left(\tau_{O}\right), \quad 0<\widetilde{\Delta}_{O}\left(\tau_{O}\right)<1-\tau_{O}$ such that

$$
\hat{p}_{O}\left(\tau_{O}\right)=p_{O}^{M A X}\left(\widetilde{\Delta}_{O}\left(\tau_{O}\right)\right)
$$

So, for $\Delta>\widetilde{\Delta}_{o}\left(\tau_{O}\right)$ the cartel stability condition will bite and the cartel will be forced to charge the maximum price. But then, from (23) in order for the cartel to be able to set a price above the "but-for" price, it is necessary that $\Delta<1-\tau_{O}$. Bringing this all together we have the following proposition.

\footnotetext{
${ }^{32}$ This result is similar to Rotemberg and Saloner (1986) who made a general point that ICC will influence the cartel pricing decisions in the presence of random variations in profits. In contrast to Rotemberg and Saloner (1986) here the random variation comes from the penalty, while in their case it comes from fluctuations in demand. In our setting the random event is that the cartel is detected and it affects sustainability condition. Our intuition is similar, but the source of random variation is different.
} 
Proposition 5: When there is an overcharge-based penalty regime that is implemented with toughness $\tau_{O}$ then:

(a) the maximum critical level of difficulty is:

$$
\bar{\Delta}_{o}\left(\tau_{O}\right)=1-\tau_{O} ;
$$

(b) for $\Delta \in[0,1]$ the overall price is:

$$
p_{O}\left(\Delta, \tau_{O}\right)=\left\{\begin{array}{l}
\hat{p}_{O}\left(\tau_{O}\right), \quad 0 \leq \Delta \leq \tilde{\Delta}_{O}\left(\tau_{O}\right) \\
p_{O}^{M A X}(\Delta), \quad \tilde{\Delta}_{O}\left(\tau_{O}\right) \leq \Delta<1-\tau_{O} . \\
c, \quad 1-\tau_{O} \leq \Delta \leq 1
\end{array}\right.
$$

The overall price is illustrated in Figure 4 below

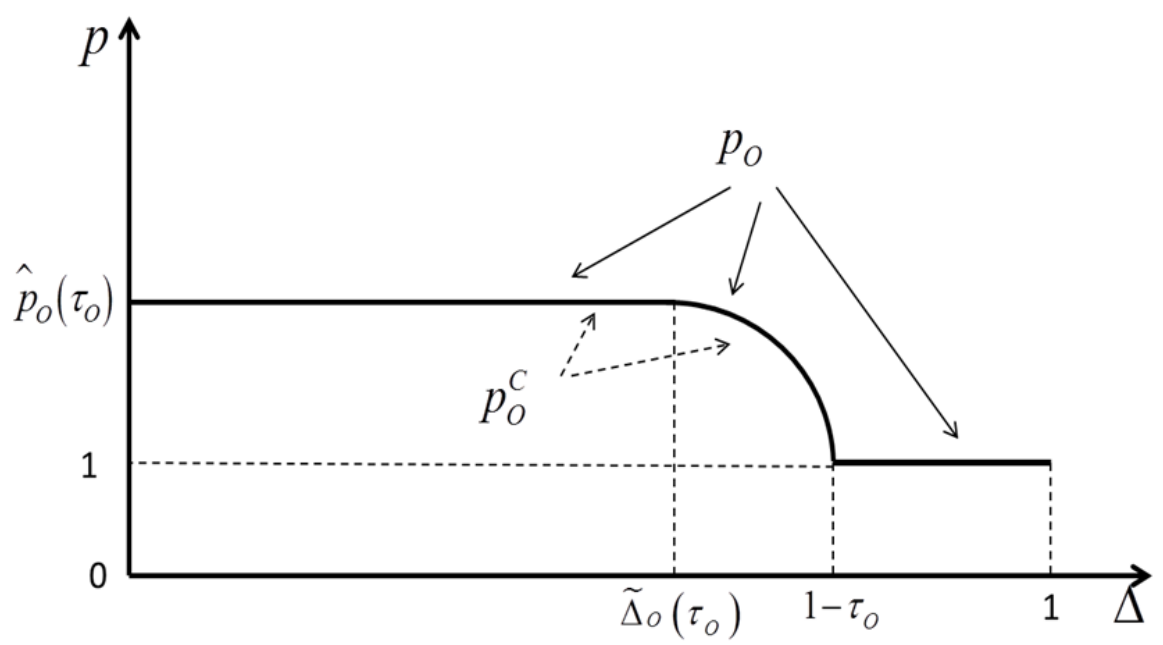

Figure 4: Overall Price under Overcharge-Based Penalty

\section{Comparisons of the Alternative Penalty Regimes}

In this section we draw on the results of the previous section to undertake an analysis of how the various welfare indicators in which we are interested - price, deterrence, average surplus etc. - are affected by the alternative penalty regimes, We investigate both withinregime factors, such as toughness, but also the effect of switching to different penalty bases.

\subsection{Comparison of Prices Set by Stable Cartels}


We start with a comparison across the three regimes of the prices set by those cartels that do form ${ }^{33}$ as established in Section 3 above. We summarize the results in the following proposition:

\section{Proposition 6:}

(a) Penalties based on either profits (illegal gains) or on revenue are ineffective in reducing the cartel price below the monopoly price. In particular:

(i) With penalties on profits the cartel price remains equal to the monopoly price, $p_{\pi}^{C}=p^{M}(c)$ and, moreover, is independent of the toughness of the profits-based regime $\tau_{\pi}$.

(ii) Penalties on revenue are distortionary and produce a cartel price that

- lies between the monopoly price and the choke price - i.e. $p^{M}(c)<p_{R}^{C}<P(0) ;$

- is strictly increasing in the toughness of the revenue-based penalty regime, $\tau_{R}$.

(b) Penalties on overcharges are effective in producing a cartel price that

- lies between the monopoly and the competitive price - i.e. $c<p_{O}^{C}<p^{M}(c)$

- is a strictly decreasing function of the toughness of the overcharge regime $\tau_{O}$;

- $\quad$ tends towards the competitive price as $\tau_{O} \rightarrow 1$.

(c) For all $\tau_{\pi}, \quad 0<\tau_{\pi}<1, \quad \tau_{R}, \quad 0<\tau_{R}<1 \quad$ and $\tau_{O}, 0<\tau_{O}<1$ $p_{O}^{C}<p^{M}(c)=p_{\pi}^{C}<p_{R}^{C}$.

The results in part (a) of the proposition can be readily established formally by an inspection of equations (8), (11), and (14). Their intuition is clear. Whatever the degree of toughness, fines based on illegal gains just produce a proportional reduction in expected profits. Consequently, maximizing net profits is equivalent to maximizing gross profits and so leads the cartel to set the same price that would have prevailed had there been no enforcement. ${ }^{34}$ However, penalties based on revenue lower expected marginal revenue but do not affect marginal cost, thus inducing cartels to cut output and drive up

\footnotetext{
${ }^{33}$ Strictly speaking, for this comparison to be valid we have to assume $0 \leq \Delta \leq \operatorname{MIN}\left[\bar{\Delta}_{\pi}\left(\tau_{\pi}\right), \bar{\Delta}_{R}\left(\tau_{R}\right), \bar{\Delta}_{O}\left(\tau_{O}\right)\right]$

${ }^{34}$ As noted above this result depends on homogeneous goods assumption. If products are differentiated, the illegal gains penalty scheme will change the collusive value as well as tighten the ICC. This will reduce the overall cartel price below the monopoly price.
} 
price. Moreover, the tougher the penalty regime the greater the reduction in expected marginal revenue and consequently output and so the higher the price.

The results in part (b) of the proposition can readily be established formally by an inspection of equations (16), (22), and (26). Intuitively, when penalties are based on the overcharge the quantity base is fixed at the but-for level and the penalty is just linear in price. Thus there is an incentive for lowering price below the monopoly level as at that level a reduction in price will lower the fine by more than the gross profits $(\pi(p))$ - so net profits will increase.

Finally, parts (a) and (b) of Proposition 6 imply that, in relation to the prices ${ }^{35}$ set by stable cartels that form, we can get a clear ranking across the three penalty regimes that is independent of the precise degree of toughness of each regime. This remarkably strong conclusion will be important in the analysis in Section 4.3

\subsection{Deterrence Effects: Comparative Static Properties}

The desirability of alternative penalty regimes depends not just on their effect on the price charged by any given cartel, but also on their effects on the number of cartels that are formed and remain stable - their effect on deterrence. In this sub-section we begin to examine these latter effects by undertaking a comparative static analysis of how the maximum critical difficulty of holding a cartel together is affected by the penalty regime and market conditions. We observe that for all three penalty regimes, the maximum critical difficulty of holding a cartel together is decreasing in the toughness of the penalty regime, and goes to zero as the degree of toughness goes to 1. This follows immediately from equations (7), (13) and (25) defining the maximum critical difficulty under all three regimes.

\subsection{Welfare Effects of Using Different Penalty Bases}

Precisely because, as we have just seen, the deterrent effects of any given penalty regime is so sensitive to the toughness with which it is implemented, it follows that the overall price and hence the various measures of average consumer surplus etc. are also going to be very sensitive to the toughness with which any given regime is implemented. So using, say, revenue rather than the overcharge as a penalty base may produce better welfare outcomes if the revenue-based penalty is implemented very toughly while the overcharge-based penalty is implemented very weakly. Consequently if we want to undertake a meaningful analysis of the consequences for various indicators of welfare price, deterrence etc. - of using different bases on which to impose penalties, we have to do so holding the degree of toughness constant in some sense. There are a number of possible interpretations of what it might mean for regimes to be equally tough. In what follows we consider two: deterrence equivalence and penalty revenue equivalence.

\footnotetext{
${ }^{35}$ And hence the associated levels of consumer surplus and total welfare.
} 
Recall also that using the expressions for overall cartel prices derived in sections $3.1,3.2$ and 3.3 and assuming that $\Delta$ is uniformly distributed on [0,1], we can calculate the average overcharge, the average consumer surplus, and the average total welfare associated with any penalty regime. These are given by

$$
\begin{aligned}
& \bar{O}[\tau B(\cdot)]=\int_{0}^{1} p[\Delta, \tau B(\cdot)] d \Delta-c \\
& \overline{C S}(\tau B(\cdot))=\int_{0}^{1} C S[p(\Delta, \tau B(\cdot))] d \Delta \\
& \overline{T W}(\tau B(\cdot))=\int_{0}^{1} T W[p(\Delta, \tau B(\cdot))] d \Delta
\end{aligned}
$$

In particular, by substituting (9) into (27) - (29) we obtain $\bar{O}_{\pi}\left(\tau_{\pi}\right), \overline{C S}_{\pi}\left(\tau_{\pi}\right), \overline{T W}_{\pi}\left(\tau_{\pi}\right)$ - the average overcharge, consumer surplus and total welfare under a profits-based regime that is implemented with toughness $\tau_{\pi}, \quad 0 \leq \tau_{\pi} \leq 1$. By substituting (14) into (27)-(29) and obtain $\bar{O}_{R}\left(\tau_{R}\right), \overline{C S}_{R}\left(\tau_{R}\right), \overline{T W}_{R}\left(\tau_{R}\right)$ - the average overcharge, consumer surplus and total welfare under a revenue-based regime that is implemented with toughness $\tau_{R}, \quad 0 \leq \tau_{R} \leq 1$. While, by substituting (26) into (27)-(29) we obtain $\bar{O}_{O}\left(\tau_{O}\right), \overline{C S}_{O}\left(\tau_{O}\right), \overline{T W}_{O}\left(\tau_{O}\right)$ - the average overcharge, consumer surplus and total welfare under an overcharge-based regime that is implemented with toughness $\tau_{o}, \quad 0 \leq \tau_{o} \leq 1$.

\subsubsection{Deterrence Equivalence}

One natural interpretation of what it might mean for each regime to be equally tough is that the fraction of cartels deterred is exactly the same across all three regimes i.e. the maximum critical difficulty is the same across all three regimes. Formally we require that the toughness parameters $\tau_{\pi}, \tau_{R}, \tau_{O}$ are such that, for some $\bar{\Delta}^{*}, \quad 0<\bar{\Delta}^{*}<1$

$$
\bar{\Delta}_{\pi}\left(\tau_{\pi}\right)=\bar{\Delta}_{R}\left(\tau_{R}\right)=\bar{\Delta}_{O}\left(\tau_{O}\right)=\bar{\Delta}^{*} .
$$

If we denote the toughness parameters for which this is true by $\tau_{\pi}^{*}, \tau_{R}^{*}, \tau_{O}^{*}$, then clearly $\tau_{\pi}^{*}=\tau_{O}^{*}=1-\bar{\Delta}^{*}$ and $\tau_{R}^{*}<1-\bar{\Delta}^{*}$. But, from Proposition 8 this immediately implies:

$$
\begin{aligned}
& \forall \Delta, \quad 0 \leq \Delta \leq \bar{\Delta}^{*}: \\
& \quad p_{O}\left(\Delta, \tau_{O}^{*}\right)=p_{O}^{C}\left(\Delta, \tau_{O}^{*}\right)<p_{\pi}\left(\Delta, \tau_{\pi}^{*}\right)=p_{\pi}^{C}\left(\Delta, \tau_{\pi}^{*}\right)<p_{R}\left(\Delta, \tau_{R}^{*}\right)=p_{R}^{C}\left(\Delta, \tau_{R}^{*}\right)
\end{aligned}
$$

and

$$
\forall \Delta, \quad \bar{\Delta}^{*} \leq \Delta \leq 1: \quad p_{O}\left(\Delta, \tau_{O}^{*}\right)=p_{\pi}\left(\Delta, \tau_{\pi}^{*}\right)=p_{R}\left(\Delta, \tau_{R}^{*}\right)=c
$$

This gives us the following proposition: 
Proposition 7: If we impose deterrent equivalence for any $\bar{\Delta}^{*}, \quad 0<\bar{\Delta}^{*}<1$ then

$$
\begin{array}{ll}
\text { (i) } & \bar{O}_{O}\left(\tau_{O}^{*}\right)<\bar{O}_{\pi}\left(\tau_{\pi}^{*}\right)<\bar{O}_{R}\left(\tau_{R}^{*}\right) \\
\text { (ii) } & \overline{C S}_{O}\left(\tau_{O}^{*}\right)>\overline{C S}_{\pi}\left(\tau_{\pi}^{*}\right)>\overline{C S}_{R}\left(\tau_{R}^{*}\right) \\
\text { (iii) } & \overline{T W}_{O}\left(\tau_{O}^{*}\right)>\overline{T W}_{\pi}\left(\tau_{\pi}^{*}\right)>\overline{T W}_{R}\left(\tau_{R}^{*}\right) .
\end{array}
$$

Proof: (i) follows by using (31) and (32) and integrating over all $\Delta \in[0,1]$. (ii) and (iii) follow by noting that consumer surplus and total welfare are strictly decreasing functions of price.

Figure 5 shows the superiority of the overcharge based regime for overall prices under deterrence equivalence.

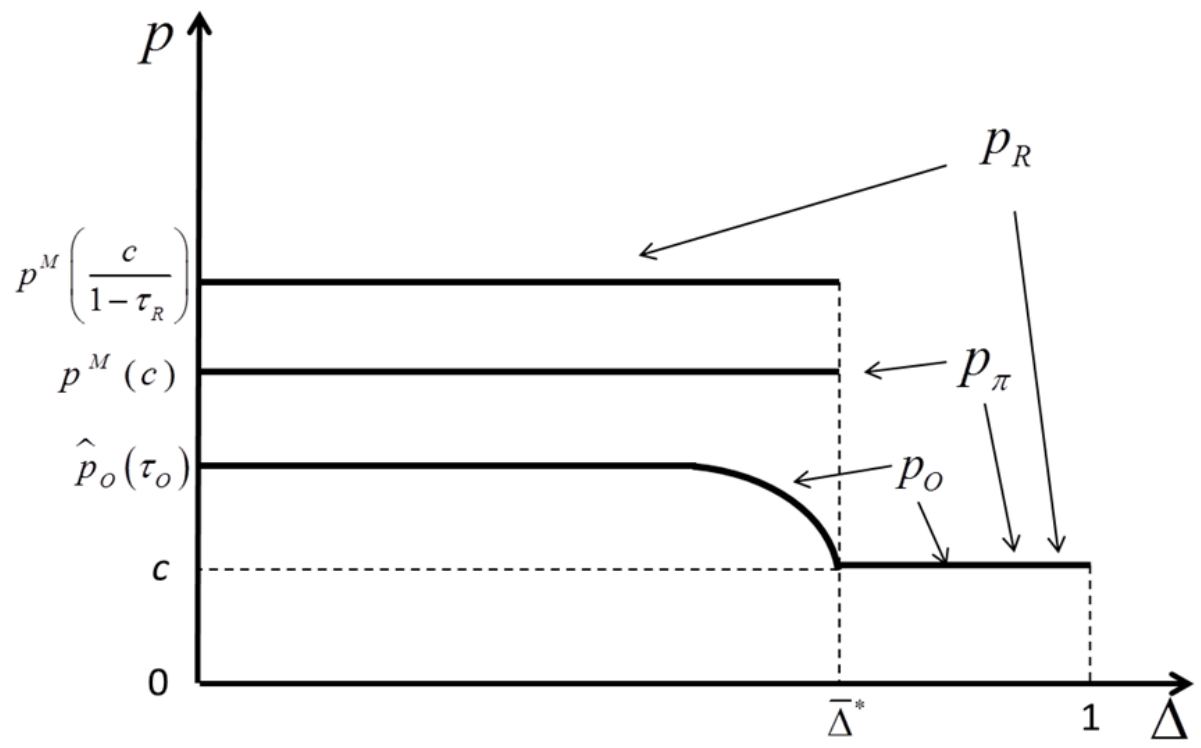

Figure 5: Overall Prices under Deterrence Equivalence

The intuition is simple. Profit or revenue based regimes could only perform better in terms of overall prices if the toughness parameters in these regimes led to cartel deterrence and thus competitive (Bertrand) pricing at even lower values of $\Delta$ (the critical difficulty of forming cartels) than the values of $\Delta$ that lead to deterrence and competitive pricing with the toughness parameter of the overcharge-based regime. Under deterrence equivalence the toughness parameters and the values of $\Delta$ above which we get deterrence and competitive pricing are equalized across the three regimes, so the overcharge regime leads unambiguously to lower overall prices. As Proposition 7 shows, whatever welfare indicator we use, an overcharge-based penalty regime welfare dominates a profit-based regime which in turn welfare dominate a revenue-based penalty regime. 
We also have the following simple corollary relating to the comparison of an overcharge-based penalty regime with a profits-based regime.

Corollary 8: If an overcharge-based regime is at least as tough as a profit-based regime then it welfare dominates the profit-based regime. Formally, for all $\left(\tau_{\pi}, \tau_{O}\right) \quad 0<\tau_{\pi} \leq \tau_{O}<1$

(i) $\bar{O}_{O}\left(\tau_{O}\right)<\bar{O}_{\pi}\left(\tau_{\pi}\right)$;

(ii) $\quad \overline{C S}_{O}\left(\tau_{O}\right)>\overline{C S}_{\pi}\left(\tau_{\pi}\right)$;

(iii) $\quad \overline{T W}_{O}\left(\tau_{O}\right)>\overline{T W}_{\pi}\left(\tau_{\pi}\right)$.

Proof: From (26) and (9) it follows that $\forall \Delta, 0 \leq \Delta<1-\tau_{\pi}$, $p_{O}\left(\Delta, \tau_{O}\right)<p_{\pi}\left(\Delta, \tau_{\pi}\right)=p^{M}(c)$, while $\forall \Delta, 1-\tau_{\pi} \leq \Delta \leq 1, \quad p_{O}\left(\Delta, \tau_{O}\right)=p_{\pi}\left(\Delta, \tau_{\pi}\right)=c$. So (i) follows by integration over $\Delta \in[0,1]$; (ii) and (iii) follow by noting that consumer surplus and total welfare are strictly decreasing functions of price.

\subsubsection{Penalty Revenue Equivalence}

An alternative notion of equal toughness is that of penalty revenue equivalence, namely that, on average ${ }^{36}$ the size of the penalty actually paid by any cartel that forms and is subsequently detected and penalized should be the same whatever penalty base is in operation. There are two related reasons for considering such a criterion.

The first is the obvious one that, since we are using different bases, which, in any given case could be of a different size - e.g. profit will be lower than revenue - then imposing a penalty at, say, $50 \%$ on one base will produce a very different revenue than imposing a penalty at $50 \%$ on the other. So rather than just comparing the rates at which various penalties are imposed, it makes sense to correct for the difference in the size of the bases by requiring that the absolute amount of penalty revenue raised is the same.

The second reason is that competition authorities and, especially, courts are not just interested in deterrence. They care about factors such as proportionality and so may not want convicted cartels to end up paying massively different fines just because a different base is used on which to impose penalties.

Unfortunately, general analysis of revenue equivalence, without specifying a particular demand function, is not feasible. So for a comparison of the effects of different penalty structures under penalty revenue equivalence we assume a linear demand structure. In that case, results 9, 10 below can be obtained. For detailed proofs see Katsoulacos et al. (2015).

\footnotetext{
${ }^{36}$ Since, as indicated, the price set by any cartel that does form, under both a revenue-based penalty regime and an overcharge-based penalty regime will potentially vary depending on the intrinsic difficulty of holding the cartel together, so will the actual penalty paid. So all we can require is that on average the penalty paid should be the same.
} 
To simplify the exposition we first compare an overcharge-based regime with a profit-based regime and then we compare a profit-based regime with a revenue-based regime.

\subsubsection{Overcharge vs Profits}

Suppose that an overcharge-based penalty regime is implemented with toughness $\tau_{O}, \quad 0<\tau_{O}<1$, and so, for any cartel that is detected and penalized, generates on average $^{37}$ the penalty revenue $\bar{F}_{O}\left(\tau_{O}\right)=\frac{\tau_{O} Q^{N}}{\beta} \cdot \frac{1}{1-\tau_{O}} \int_{0}^{1-\tau_{O}}\left[p_{O}^{C}\left(\Delta, \tau_{0}\right)-c\right] d \Delta$. While the penalty revenue generated under the profit-based regime is given by $\bar{F}_{\pi}\left(\tau_{\pi}\right)=\rho_{\pi} \pi^{M}(c)=\frac{\tau_{\pi}}{\beta} \pi^{M}(c)$, which is directly proportional to the toughness of the profits-based penalty regime. ${ }^{38}$

If we let $\tau_{\pi}^{e}\left(\tau_{O}\right)$ denote the toughness of the profits-based penalty regime that is penalty revenue equivalent to $\tau_{O}$ then this is defined by the condition:

$$
\bar{F}_{\pi}\left[\tau_{\pi}^{e}\left(\tau_{0}\right)\right]=\bar{F}_{O}\left(\tau_{O}\right)
$$

which under linear demand structure specified in Katsoulacos et al. (2015) implies:

$$
\tau_{\pi}^{e}\left(\tau_{o}\right)=\frac{2 \tau_{O}}{1-\tau_{O}}\left\{\left(1-\tau_{o}\right)-2 \tau_{o}\left[\ln (2)-\ln \left(1+\tau_{o}\right)\right]\right\} .
$$

However, because $\bar{F}_{O}\left(\tau_{O}\right)$ is inverse $\mathrm{U}$-shaped with $\bar{F}_{O}\left(\tau_{O}\right) \rightarrow 0$ as $\tau_{O} \rightarrow 1$ so too will be $\tau_{\pi}^{e}\left(\tau_{o}\right)$. In other words because a very tough overcharge based regime will erode the penalty base and drive penalty revenue to zero as $\tau_{O} \rightarrow 1$, if the only condition we imposed for revenue equivalence was (33) we would end up comparing extremely tough overcharge-based regimes with extremely weak profit-based regimes, which would violate our requirement that these regimes are equally tough. So the second condition we impose to ensure equal toughness is that we confine attention to values of $\tau_{o} \in(0,1)$ for which $\tau_{\pi}^{e}\left(\tau_{0}\right)$ is monotonic increasing. ${ }^{39}$

\footnotetext{
${ }^{37}$ Because the overcharge varies with the critical level of difficulty $\Delta \in\left[0, \bar{\Delta}\left(\tau_{R}\right)\right]$ so too will the precise penalty revenue obtained, so all we can determine is the average penalty revenue.

${ }^{38}$ Note that it is equal to the average fine that is paid by any cartel that is detected and penalized.

${ }^{39}$ It is straightforward to show that this restriction implies $\tau_{O} \leq 0.465, \tau_{\pi} \leq 0.427$. Following the work of Bryant and Eckard (1991), it is widely accepted that in practice the annual probability of detection is about $15 \%$. However, it is plausible to assume that the time it takes cartel members to spot a deviation and react to it by implementing the grim trigger strategy is less than a year. The relevant per period probability of detection is that of being detected over this much shorter interval of time, and so the relevant value of $\beta$ is $<0.15$ (see also Buccirossi and Spagnolo (2007) or Harrington and Wei (2014)). The discussion in Section 1 suggests that the maximum penalty rate that is ever likely to be imposed on profits
} 
Having defined $\tau_{\pi}^{e}\left(\tau_{O}\right)$ we can use (27) $\quad-$ (29) to define $\bar{O}_{\pi}\left[\tau_{\pi}^{e}\left(\tau_{0}\right)\right], \overline{C S}_{\pi}\left[\tau_{\pi}^{e}\left(\tau_{0}\right)\right], \overline{T W}_{\pi}\left[\tau_{\pi}^{e}\left(\tau_{0}\right)\right]$ which are, respectively the average overcharge, consumer surplus and total welfare that would accrue under a profits-based regime that was implemented with a degree of toughness that is penalty-revenue equivalent to the degree of toughness $\tau_{O}$ with which the overcharge-based penalty regime is implemented. We then have the following result.

Result 9: If we impose penalty-revenue equivalence then under a linear demand structure:

$$
\begin{aligned}
& \bar{O}_{O}\left(\tau_{O}\right)<\bar{O}_{\pi}\left[\tau_{\pi}^{e}\left(\tau_{O}\right)\right] \\
& \overline{C S}_{O}\left(\tau_{O}\right)>\overline{C S}_{\pi}\left[\tau_{\pi}^{e}\left(\tau_{O}\right)\right] \\
& \overline{T W}_{O}\left(\tau_{O}\right)>\overline{T W}_{\pi}\left[\tau_{\pi}^{e}\left(\tau_{O}\right)\right]
\end{aligned}
$$

Proof: For detailed proofs see Appendix 2 in Katsoulacos et al. (2015).

So in terms of all our welfare criteria an overcharge-based penalty regime welfare dominates a profits-based regime that is implemented with a penalty-revenue-equivalent degree of toughness. ${ }^{40}$

\subsubsection{Profits vs Revenue}

Note that under a revenue-based regime the average penalty that is paid by any cartel that is detected and penalized is given by

$$
\bar{F}_{R}\left(\tau_{R}\right)=\frac{\tau_{R}}{\beta} p^{M}\left(\frac{c}{1-\tau_{R}}\right) \cdot Q\left[p^{M}\left(\frac{c}{1-\tau_{R}}\right)\right]
$$

Similar to section 4.3.3.1 we let $\tau_{\pi}^{e}\left(\tau_{R}\right)$ denote the toughness of the profits-based penalty regime that is penalty revenue equivalent to $\tau_{R}$ then this is defined by the condition:

$$
\bar{F}_{\pi}\left[\tau_{\pi}^{e}\left(\tau_{0}\right)\right]=\bar{F}_{R}\left(\tau_{R}\right)
$$

Now because under the linear demand structure specified in Katsoulacos et al. (2015) $\bar{F}_{R}\left(\tau_{R}\right)$ is inverse U-shaped with $\bar{F}_{R}(0)=0 ; \bar{F}_{R}\left(\tau_{R}\right) \rightarrow 0$ as $\tau_{R} \rightarrow 1$ so too will

is $200 \%$. Taken together this implies that in practice $\tau_{\pi}=\beta \rho_{\pi}<0.3$ and so restricting attention to the range of values for which $\tau_{\pi}^{e}\left(\tau_{O}\right)$ is monotonic increasing is fully consistent with the range of values for the toughness of profits-based regimes that we see in practice.

${ }^{40}$ As discussed in Katsoulacos et al. (2015), switching from a profit to an overcharge-based regime could well involve some balancing of the desire to achieve revenue equivalence and deterrence equivalence. Proposition 11 of that paper generalizes the Result 9 above showing that however one chooses to strike this balance the switch is unambiguously welfare improving. 
be $\tau_{\pi}^{e}\left(\tau_{R}\right)$. So, just as in the previous sub-section, the second condition we impose to ensure equal toughness is that we confine attention to values of $\tau_{R} \in(0,1)$ for which $\tau_{\pi}^{e}\left(\tau_{R}\right)$ is monotonic increasing.

Having defined $\tau_{\pi}^{e}\left(\tau_{R}\right)$ we can use (27) - (29) to define $\bar{O}_{\pi}\left[\tau_{\pi}^{e}\left(\tau_{R}\right)\right], \overline{C S}_{\pi}\left[\tau_{\pi}^{e}\left(\tau_{R}\right)\right], \overline{T W}_{\pi}\left[\tau_{\pi}^{e}\left(\tau_{R}\right)\right]$ which are, respectively the average overcharge, consumer surplus and total welfare that would accrue under a profits-based regime that was implemented with a degree of toughness that is penalty-revenue equivalent to the degree of toughness $\tau_{R}$ with which the revenue-based penalty regime is implemented. Hence, we have the following powerful result:

Result 10: If we impose penalty-revenue equivalence then, under a linear demand structure:
(i)
$\bar{O}_{R}\left(\tau_{R}\right)>\bar{O}_{\pi}\left[\tau_{\pi}^{e}\left(\tau_{R}\right)\right]$
(ii)
$\overline{C S}_{R}\left(\tau_{R}\right)<\overline{C S}_{\pi}\left[\tau_{\pi}^{e}\left(\tau_{R}\right)\right]$
(iii)

$$
\overline{T W}_{R}\left(\tau_{R}\right)<\overline{T W}_{\pi}\left[\tau_{\pi}^{e}\left(\tau_{R}\right)\right]
$$

Proof: For detailed proofs see Appendix 3 in Katsoulacos et al. (2015).

So in terms of all our welfare criteria a revenue-based penalty regime is unambiguously dominated by a profits-based regime that is implemented with a penaltyrevenue-equivalent degree of toughness.

The overall conclusion that emerges given these results is that whether one uses deterrence equivalence or penalty-revenue equivalence as a way of equating the degree of toughness of the various regimes, an overcharge-based regime welfare dominates a profits-based regime which in turn welfare dominates a revenue-based regime.

\section{Concluding Remarks}

We analyze the impact of various antitrust penalty regimes on: (i) the price charged by any given cartel; (ii) cartel stability; and finally, (iii) the overall level of consumer and total welfare induced by the different regimes.

For this analysis we use a repeated Bertrand oligopoly model that allows us to compare both the price and the deterrence effects of the four major types of fining structures. These four types include fines based on revenues, fines based on illegal gains, fines based on the cartel overcharge, and fixed fines. Further, we show that when penalties are introduced on either revenue or on the cartel overcharge then the cartel stability condition can influence the price set by the cartel. The general point that ICC 
will influence the pricing decisions in the presence of random variations in profits has been made in Rotemberg and Saloner (1986). In contrast to Rotemberg and Saloner (1986) here random variation comes from the expected penalty, while in their case it comes from fluctuations in demand. The proposed novel framework allows us to bridge the standard critical discount factor approach to the analysis of collusion (see e.g. Tirole (1988) or Motta and Polo (2003)) to profit-maximizing decisions by the cartel members (with continuum of prices, which can be chosen by the cartel). This latter approach has been proposed in e.g. Block et al. (1981) or Harrington (2004, 2005).

While other papers have considered the properties of the four penalty regimes and made some limited comparisons between them, the contribution of this paper is to undertake a systematic comparison of all four regimes in terms of both the prices set by those cartels that form and on cartel stability (deterrence) and hence the number of cartels that form. We examine deterrence under both deterrence equivalence and penaltyrevenue equivalence.

Our analysis leads to the conclusion that there is absolutely no support from welfare economics for the currently widely utilized fining structures (mainly based on revenues). Penalties based on overcharges are welfare superior to all three other penalty structures considered in this paper. There are other penalty bases that could be considered. However to the extent that these involve a combination of the penalty bases considered here - for example a fixed penalty combined with an overcharge-based penalty - then, the welfare outcomes are likely to be a combination of the welfare outcomes under each of the component terms in the penalty base and so will not produce higher welfare levels than a pure overcharge-based regime - provided of course that, as here, the comparison is done imposing a condition of equal toughness.

We have confined attention to linear penalty structures. The extension of our analysis to non-linear penalty structures remains an interesting research direction.

While it has not been our main purpose in this paper to go into issues of implementation of an alternative penalty regime based on overcharges there are a number of points that should be made. First, developments in economics and econometrics make it possible to estimate overcharges from a cartel infringement with reasonable precision or confidence, as is regularly done to assess damages. Second, the question of which penalty regime to implement must be answered taking into account both relative welfare levels induced under each regime and the relative costs of implementation. Third, to the extent that parties engage in private damage claims the costs of calculating the but-for price are already being incurred by society, and there may be some gains in avoiding duplication by having competition authorities perform the calculation in order to assess the appropriate overcharge penalty. Fourth, there could be further cost reductions by requiring firms to contribute to the costs of gathering reliable data required to perform the calculations of the but-for price and output. ${ }^{41}$

\footnotetext{
${ }^{41}$ We are grateful to Giancarlo Spagnolo for pointing this out to us.
} 
To paraphrase the position already expressed recently in another paper it is probably time to change the distortive policies currently utilized - that make revenue so central for calculating fines, if the only thing the welfare costs of the distortions buy for us is saving the costs of data collection and overcharges estimation. ${ }^{42}$

\section{References}

Allain, M-L, Boyer, M., Kotchoni, R. \& J-P. Ponssard, (2011) "The Determination of Optimal Fines in Cartel Cases: The Myth of Underdeterrence”, CIRANO Discussion Paper 2011s-34

Bageri, V., Y. Katsoulacos, and G. Spagnolo (2013) "The Distortive Effects of Antitrust Fines Based on Revenue", The Economic Journal, 123 (572), 545-557.

Becker, G.S. (1968) "Crime and Punishment: An Economic Approach," Journal of Political Economy, 76, 169-217.

Block, M., F. Nold, and J. Sidak (1981) "The deterrent effect of antitrust enforcement," Journal of Political Economy 89, 429-445.

Boyer M. and R. Kotchoni (2011) "The Econometrics of Cartel Overcharges", CIRANO Discussion Paper, 2011s-35

Brander, J.A. and T.W. Ross (2006), "Estimating Damages from Price-Fixing", Canadian Class Action Review, 3(1), 335 - 369.

Bryant, P.G., and E.W. Eckard (1991) "Price Fixing: The Probability of Getting Caught," The Review of Economics and Statistics, 73, 531-536.

Buccirossi, P. and G. Spagnolo (2007) "Optimal Fines in the Era of Whistleblowers - Should Price Fixers Still Go to Prison?" in The Political Economy of Antitrust, by V. Goshal and J. Stennek (Eds.), Elsevier: Amsterdam.

Chen, Z. and P. Rey (2007) "On the design of leniency programs," IDEI working paper number 452 (revised 2012)

Cyrenne, P. (1999) "On antitrust enforcement and the deterrence of collusive behavior," Review of Industrial Organization 14, 257-272.

Dargaud E., A. Mantovani and C. Reggiani (2015) "Cartels deterrence and distortive effects of fines", mimeo.

\footnotetext{
${ }^{42}$ Bageri et.al. (2013) also make this point in a static setting having compared revenue and profit-based regimes and arguing in favor of the latter. In our repeated game setting we also find that a profit-based regime is welfare superior to a revenue-based regime. In addition, we show that an overcharge-based regime is superior to a profit-based regime.
} 
EC (2006) "Guidelines on the Method of Setting Fines Imposed Pursuant to Article 23(2)(a) of Regulation no 1/2003," Official Journal of the European Union (2006/C 210/02), Brussels.

Fudenberg, D. and J. Tirole (1991) Game Theory, MIT Press: Cambridge.

Harrington, J. (2004) "Cartel Pricing Dynamics in the Presence of an Antitrust Authority," The Rand Journal of Economics 35, 651-673.

Harrington, J. (2005) "Optimal Cartel Pricing in the Presence of an Antitrust Authority," International Economic Review 46, 145-170.

Harrington J. (2010) "Comment on Antitrust Sanctions," Competition Policy International 6, 41 51.

Harrington, J. (2014), "Penalties and the deterrence of unlawful collusion", Economics Letters, 124, 33-36.

Harrington J. and J. Chen (2007) "The impact of the corporate leniency program on cartel formation and the cartel price path. In V. Ghosal and J. Stennek (Eds.), The Political Economy of Antitrust. Elsevier.

Harrington J. and Y. Wei (2014) "What can the duration of discovered cartels tell us about the duration of cartels", mimeo, University of Pennsylvania

Houba, H., E. Motchenkova, and Q. Wen (2010) "Antitrust enforcement with price-dependent fines and detection probabilities," Economics Bulletin, 30(3), 2017-2027.

Houba, H., E. Motchenkova, and Q. Wen (2011) "Antitrust Enforcement and Marginal Deterrence," (2011) Tinbergen Institute Discussion Papers 11-166/1.

Houba, H., E. Motchenkova, and Q. Wen (2012) "Competitive Prices as Optimal Cartel Prices," Economics Letters 114, 39-42.

Houba, H., E. Motchenkova, and Q. Wen (2014) "The Role of Legal Principles in the Economic Analysis of Competition Policy", in Analysis of Competition Policy and Sectoral Regulation, M. Peitz and Y. Spiegel eds., Now Publishers Inc. Boston-Delft. pp. 389-422.

Houba, H., E. Motchenkova, and Q. Wen (2015) "The effects of leniency on cartel pricing," forthcoming in BE Journal of Theoretical Economics

Hunold, M. (2013) "Essays in Competition Economics", Chapter 3 of PhD Dissertation, University of Mannheim, http://d-nb.info/1037311698/34 
Jensen, S. and L. Sorgard (2012) "Enforcement with heterogeneous cartels," Working paper 14/12, Institute for Research in Economics and Business Administration, Norway.

Jensen, S. and L. Sorgard (2014) "Fine schedule with heterogeneous cartels: Are the wrong cartelsdeterred?," mimeo, Institute for Research in Economics and Business Administration, Norway.

Katsoulacos, Y. and D. Ulph (2013) "Antitrust Penalties and the Implications of Empirical Evidence on Cartel Overcharges", The Economic Journal, 123 (572), 558-581.

Katsoulacos, Y., Motchenkova, E. and D. Ulph, (2015). "Penalizing Cartels: The Case for Basing Penalties on Price Overcharge", Research Memorandum, no 2015-5, Amsterdam: Faculty of Economics and Business Administration (also in Discussion Paper Series, Department of Economics, University of St. Andrews and CRESSE 2015 publications: http://www.cresse.info/uploadfiles/PenalizingCartels14042015.pdf)

Levenstein, M. C. and V. Y. Suslow (2011), "Breaking Up Is Hard to Do: Determinants of Cartel Duration", Journal of Law and Economics 54, 455- 92.

Levenstein, M. C. and V. Y.Suslow(2012), "Cartels and Collusion - Empirical Evidence". Ross School of Business Paper No. 1182. Available at SSRN: http://ssrn.com/abstract=2182565

Levenstein, M. C. and V. Y.Suslow (2014) "Price fixing hits home: an empirical study of price fixing conspiracies in the US", mimeo, University of Michigan, Jan. 2014.

Motta, M. and M. Polo (2003) "Leniency Programs and Cartel Prosecution," International Journal of Industrial Organization 21, 347-379.

OECD (2002) "Fighting Hard-Core Cartels: Harm, Effective Sanctions and Leniency Programs" OECD Report 2002, OECD, Paris, France, http://www.SourceOECD.org.

Rey, P. (2003) "Towards a Theory of Competition Policy" in Advances in Economics and Econometrics: Theory and Applications by M. Dewatripont, L. Hansen, and S. Turnovsky, Eds., Cambridge University Press.

Rotemberg, J. and G. Saloner (1986) “A Supergame-Theoretic Model of Price Wars during Booms", The American Economic Review, Vol. 76, No. 3, pp. 390-407

Spagnolo, G. (2004) "Optimal leniency programs," CEPR Discussion paper series, working paper number 4840, (revised 2008)

USSG (2010) "US Sentencing Guidelines (Chapter 8: Sentencing of organizations)" http://www.ussc.gov/2009guid/CHAP8.htm

Wils, W. (2007) "The European Commission's 2006 Guidelines on Antitrust Fines: A Legal and Economic Analysis" in World Competition 30. 